\title{
Research on the Influence of Volatility of International Energy Commodity Futures Market on CPI in China
}

\author{
Keyao Lin, ${ }^{1}$ Chao Xun $\left(\mathbb{D},{ }^{1}\right.$ Fei Wang, ${ }^{2}$ Angela Chi Chao, ${ }^{3}$ and Zhenyu Du ${ }^{3}$ \\ ${ }^{1}$ State Grid Fujian Electric Power Company, Fu Zhou 350003, Fu Jian, China \\ ${ }^{2}$ National Tax Institute of STA, Yangzhou 210023, Jiangsu, China \\ ${ }^{3}$ School of Economics and Management, Southeast University, Nanjing 211189, Jiangsu, China \\ Correspondence should be addressed to Chao Xun; cclinda@yandex.ru
}

Received 21 May 2021; Accepted 28 July 2021; Published 3 August 2021

Academic Editor: Xiaoqing Bai

Copyright (C) 2021 Keyao Lin et al. This is an open access article distributed under the Creative Commons Attribution License, which permits unrestricted use, distribution, and reproduction in any medium, provided the original work is properly cited.

This article analyses the transmission path of the international commodity futures market's impact on the Chinese economy. We use the MIDAS model and daily data to predict China's CPI in real time. Empirical analysis results show that (1) the influence of high-frequency explanatory variables on low-frequency CPI is different. The optimal lag orders of domestic high-frequency variables are all around 23, which can be regarded as one month in practice, indicating that their CPI influence takes one month to show. (2) Both the univariate MIDAS model and the multivariate MIDAS combined prediction model have good performance in prediction accuracy. (3) The predicted results of the multivariate MIDAS combined prediction model for CPI in China's normal months are relatively excellent. However, when exceptional circumstances occur, the prediction results will show a specific deviation, and the prediction accuracy will also be reduced. Finally, some feasible suggestions are put forward according to the research results.

\section{Introduction}

The stability of energy commodity markets is crucial to the global economy. On the one hand, energy commodities provide the industrial materials necessary for economic development and guarantee sustainable expansion and reproduction. On the other hand, speculative investments in energy commodities have caused abnormal volatility in financial markets and consequently affected economic stability. COVID-19 epidemic in 2020 has had a significant negative impact on all countries and the global economy has been struck hard. Although the epidemic is gradually being brought under control in all countries with vaccination, the recovery rate globally, except China, is still weak. In this context, a stable and reliable energy supply has drawn sufficient attention from China. To address this issue, scholars have conducted studies from multiple perspectives $[1,2]$. At the moment, the global economy is underperforming and various economies are trying their best to seek recovery measures. Therefore, it is increasingly critical to analyze the impact of international energy commodities on the domestic economy.

International commodity markets have been the focus of scholars in the study of shocks from external financial markets. The commodity market has a long history and plays a vital role in contemporary economic life. Bulk commodities have financial and commodity attributes. They are the basic raw materials used in industrial production and can be used as a tool to predict global economic development trends $[3,4]$. In recent years, as commodities' financial attributes have become stronger and stronger, people have also regarded commodity futures as a financial investment tool. Especially, when the major economies have not fully recovered and the global stock market has not performed well, hot money is flowing in and out of the stock market and the commodity futures market rapidly, which has a significant impact on the economic and financial development of other regions.

Since joining the WTO, China has played an increasingly prominent role in global economic growth, and its ties with 
other regions have become increasingly close [5]. In recent years, China's relatively high economic growth rate has made its dependence on imports of bulk commodities remain high. The global share of domestic consumption of several major bulk commodities has shown an upward trend. In 2017, China's coal and steel consumption accounted for $65.2 \%$ and $46.7 \%$ of the world's total consumption, respectively, making China the world's largest coal and steel consuming country, showing a relatively apparent demand in short supply [6]. Therefore, studying the bulk commodity market has an essential guiding role in economic growth. In addition, discovering the frequency and magnitude of price fluctuations in the international commodity futures market, exploring how price fluctuations in the international commodity futures market affect China's economy, and analyzing the transmission mechanism between different markets are all very valuable issues. Finally, reasonable predictions of future fluctuations based on the research results, and then formulating measures to deal with commodity price fluctuations to curb the economic downturn, are of great significance for maintaining national economic security and stability.

\section{Literature Review}

The research on the international commodity market's impact on China's economy is mainly divided into price channel transmission and financial channel transmission. The former refers to the direct transmission of international commodity prices to the domestic macro economy, such as through price levels and industrial chains; the latter refers to the transmission of the domestic macro economy through the intermediate variable of China's financial market, such as the capital market and currency market.

\subsection{Price Channel}

2.1.1. Price Level. Most scholars believe that fluctuations in international commodity markets are transmitted through the domestic price level and that different regions are affected differently. The transmission of oil price changes to inflation is relatively low in CEE countries [7]. Moreover, there is an asymmetric behavior between oil spot prices and inflation rates [8], and deviations in oil price forecasts may affect deviations in inflation forecasts [9]. Joshi and Acharya established a VAR model and found that the co-integration relationship between commodity prices and India's domestic inflation data is becoming stronger [10]. Estrades and Terra used the DSGE model to find that the increase in commodity prices positively affects domestic economic development [11]. Filis believes that fluctuations in international oil prices can significantly affect the inflation levels of importing and exporting countries [12].

2.1.2. Industry Chain. Price changes in the international bulk commodity market can be directly transmitted to the material economy through the industrial chain and cause changes in the price level. Rising international oil prices increase the production cost of energy-intensive products using petroleum-related products as raw materials, which is not conducive for the export of such products [13] and the international commodity prices' transmission effect is from the upstream to the downstream of the industrial chain [14]. Fluctuations in the international bulk commodity market can also be transmitted between industries, thereby affecting a country's macroeconomics. Oil price fluctuations have been transmitted to various countries' macroeconomics through the industrial chain linkages under economic integration [15]. Price fluctuations in the international bulk commodity market will also affect a country's foreign trade situation. Blattman et al. analyzed the data of 35 commodity exporting countries and believed that trade fluctuations caused by the violent fluctuations of commodity prices would reduce foreign investment and thereby affect the economic growth of these countries [16].

\subsection{Financial Channel}

2.2.1. Capital Market Channel. Volatility in the international bulk commodity market will be transmitted to the material economy through the linkage effect of domestic and foreign financial markets. Many scholars have researched this transmission channel. Rudiger and Fischer believed that by influencing a country's import and export and international trade balances, the exchange rate would affect the country's economy and corporate investment, and ultimately affect the company's stock price on the stock market [17]. Buyuksahin and Robe found that the strength of the spillover effect between the international commodity market and the stock market is related to the strength of the commodity's financial attributes [18]. Quadrini believes that the material economy sector will be affected by asset price fluctuations, and this impact needs to be achieved through the credit path [19]. Hammersland et al. used two mutually reinforcing financial accelerator mechanisms to explain that financial accelerators can magnify asset prices' effect on the material economy [20].

\subsubsection{Currency Market Channel. In terms of currency} transmission channels, many scholars have discussed from the perspective of interest rates and credit. In the neoclassical price mechanism proposed by Jorgenson and Tobin [21, 22], monetary policy can affect the material economy by adjusting short-term interest rates. Jain and Ghosh found that international commodity prices significantly impact a country's currency exchange rate [23]. Credit has also played a vital role in economic development. Oliner and Rudebusch explained the credit mechanism's role in the transmission of monetary policy by studying the relationship between corporate investment and financing, in which small firms are the main transmission carriers of the credit mechanism [24]. Hume and Sentence studied the relationship between global credit peaks and the macroeconomic environment [25]. They believed that the credit peaks since the mid-1990s had no significant impact on high-speed economic growth and inflation. 
2.3. Literature Summary. It can be seen from the above that most scholars study the impact of commodity market price fluctuations on China's macroeconomic variables such as prices and output. In addition, the generalization of the transmission channels is not the same, and most scholars have not fully considered the transmission of the international commodity market to the material economy with the Chinese commodity futures market as an intermediate variable. Based on this, this article reclassifies the transmission channels. In addition, in terms of research methods, commodity futures markets are highfrequency daily data, while many economic variables are low-frequency data published monthly, quarterly, and annually. Such frequency differences will lead to forced frequency reduction in research by many scholars. Such processing methods will lose the information in the highfrequency data and reduce the credibility of the research. Therefore, it is necessary to seek new models to process data of different frequencies. Thus, this article adopts the MIDAS model and introduces the mediation effect and the moderating effect, which is a supplement to the research on the mixing data model and an innovation in macroeconomic forecasting. On the one hand, MIDAS can overcome the errors and limitations caused by studying variables of different frequencies, and the results obtained are more accurate. On the other hand, prediction research based on mixed frequency data helps to make reasonable expectations and inferences about current and future economic trends, and assists in the formulation of national macroeconomic policies.

\section{Transmission Path}

After sorting out previous studies, this article reorganizes the transmission path and summarizes the impact of the international commodity futures market on the Chinese economy into three routes as seen in Figure 1: the material economy, the financial market, and the exchange rate. The first is that the international commodity futures market affects different sectors of the domestic industrial chain. The second is the link between domestic and international commodity futures markets. The third is to affect trade prices through changes in RMB's exchange rate against the US dollar.

3.1. Material Economy Route. This route refers to the fact that international commodity futures directly affect domestic consumer prices through international trade, affect domestic producer prices, and ultimately transmit to domestic consumer prices. Therefore, the domestic production sector plays an intermediary role. As China imports a large amount of bulk commodities, domestic bulk commodities' prices will be directly affected by international market prices and are extremely sensitive to fluctuations in international commodity futures prices. Specifically, when a certain commodity price increases and is imported into the country, the price of industrial products in the domestic industrial chain will also increase.

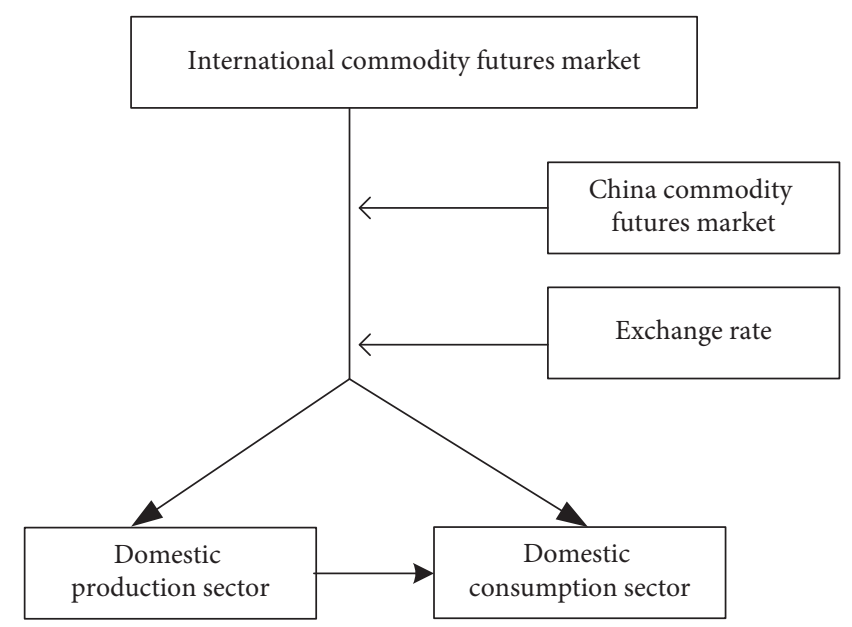

FIgURE 1: The path of international commodity futures market impact on CPI in China.

3.2. Financial Market Route. This route means that the prices of international commodity futures affect the domestic commodity futures market and the domestic economy. Due to the close links between global financial markets, price changes in the international commodity futures market will be quickly transmitted to the domestic commodity futures market, which is a short-term impact. In this process, due to the existence of capital controls in China's financial market, actual transmission may be lagging and insignificant compared to theory. In addition, futures play the role of price discovery. When prices in the international commodity futures market fluctuate, the domestic commodity futures market will change accordingly, which will then be transmitted to the material economy through price channels and affect the domestic consumer sector. This stage involves macro factors such as price levels, so the impact is relatively long term and indirect.

3.3. Exchange Rate Route. This route means that international commodity futures prices will affect various domestic production and consumption fields through the exchange rate. Generally speaking, the extent to which the international market price of a certain type of commodity can impact the domestic economy through a country's exchange rate is closely related to the proportion of imports of that type of commodity in the total supply. If the import proportion is large, then the fluctuation of its international price will have a greater impact through the exchange rate, otherwise it will not. At present, China belongs to the former situation. As China has a strong import dependence on bulk commodities, the transmission of rising international bulk commodity prices to the domestic economy will be affected mainly by the RMB exchange rate fluctuation.

To sum up, when the price of the international commodity futures market fluctuates, its impact will be directly transmitted to the domestic consumer sector on the one hand. On the other hand, it will be transmitted to the domestic consumer sector through the domestic production sector's intermediary variable. 


\section{Data and Model}

4.1. Data. The variables used in this paper include international commodity futures price index, Nanhua futures commodity index, average daily coal consumption of six major power plants, exchange rate, and consumer price index (CPI). This paper selects the daily and monthly data of relevant variables from January 2010 to January 2020 as the research object.

International commodity futures market: there are many international commodity futures market indicators, and the most representative one is the CRB series price index, including spot price index and the futures price index. Since the international commodity futures trading volume is much larger than the spot trading volume and the fluctuations are more significant, it is more suitable to use the futures index as a variable. Therefore, this paper selects the $\mathrm{RJ} / \mathrm{CRB}$ futures price composite index to measure the international bulk commodity price.

China's commodity futures market: we chose Nanhua Futures Commodity Index to represent the domestic commodity futures market. It was launched by the Nanhua Futures Exchange in 2004 and optimized from a price index to an investment index in 2008. The index provides investors with a more scientific and reasonable reference standard for futures investment returns.

Domestic production sector: we chose the average daily coal consumption of the six major power generation groups to represent the domestic production sector. Power generation has a very direct connection with industrial production. The average daily coal consumption of the six major power generation groups is often used to track industrial production. The coal consumption of the six power generation groups is the sum of the six power plants' coal consumption located in the southeast coastal area. The coal consumption of the six major power generation groups is daily high-frequency data, which can predict the changes in the country's total power generation to a certain extent, reflecting the changes in macro-industrial economic indicators.

Exchange rate: exchange rate is one of the most easily affected variables. The international bulk commodities are generally priced in US dollars, and the impact of exchange rates must be considered when influencing China's price level. Considering the availability of data, this article adopts the daily data of the US dollar against the RMB central parity.

Domestic consumption sector: we chose the consumer price index to represent the domestic consumption sector. The consumer price index is selected as the proxy variable of the national downstream price level. Its statistical scope covers all aspects of the national urban and rural residents' consumption. Simultaneously, it has good stability and can better reflect the domestic downstream consumption price level.

According to the sample frequency and availability, the sample window selected for model estimation is from January 2010 to January 2020, with 2367 observations for each set of high-frequency daily data and 121 observations low-frequency monthly data. We chose data from January 2010 to December 2018 for the in-sample forecast and January 2019 to January 2020 for the out-of-sample forecast. Given that CPI is monthly data, seasonal effects are excluded from the original data. The above data are from Wind and China Economic Network database.

4.2. MIDAS Model. The Mixed Data Sampling (MIDAS) model proposed by Ghysels can make full use of the information of the original data without processing the mixed frequency data. The MIDAS model has been studied and applied by many scholars, and the model form has been more expanded. At first, the MIDAS model was used to predict financial market fluctuations. Now, the MIDAS model has been widely used in analyzing and predicting future macroeconomic trends. The existing research mainly uses the MIDAS model to forecast macroeconomic variables of a country.

\section{Empirical Analysis}

In this part, six weight function regression models of BetaMidas, Beta-nonzero-MIDAS, Exp-Almon-Midas, StepfunMidas, and Almon-Midas are used to study the prediction effect of each high-frequency explanatory variable on CPI, and the lag order of high-frequency variables starts from the first order to the optimal order. In parameter estimation, the optimal weight function is selected according to the principle that the smaller the error is, the greater the goodness of fit is. The errors include Root Mean Square Error (RMSE), Mean Squared Error of Forecast (MSFE), and Discounted Mean Squared Error of Forecast (DMSFE). RMSE, MSFE, and DMSFE of each model are used to reflect the prediction accuracy when making the in-sample forecast. The optimal weight function and the optimal lag order are selected according to the model's output and prediction accuracy. In the empirical analysis, we compare the models' fitting results and prediction accuracy with and without autoregressive terms. The results show that the fitting results and prediction accuracy of the model are better with an autoregressive term.

5.1. Univariate MIDAS Model. When the explanatory variable is the RJ/CRB International Commodity Futures Index, the goodness of fit and in-sample and out-of-sample prediction accuracies at different lag orders are shown in Table 1 (due to limited space, only part of the lag order results and the selected mixing model are shown in this paper). We found that the RMSE of Beta-AR(1)-MIDAS, Beta non-zeroAR(1)-MIDAS, and Exp Almon-AR(1)-MIDAS are more stable compared to the others. When the lag order equals 13, the RMSE, MSFE, and DMSFE of Almon-AR(1)-MIDAS model are $0.5046,0.2546$, and 0.0868 , respectively, which is a better prediction accuracy than other models. After the lag order increases, the goodness of fit and prediction accuracy are both higher than that of lag order 13. Therefore, the Almon-AR(1)-MIDAS (13) has the highest in-sample prediction accuracy for the low-frequency CPI. As shown in Figure 2, the fluctuation range of the 13 coefficients 
TABLE 1: RJ/CRB International Commodity Futures Index: the goodness of fit and in-sample and out-of-sample prediction accuracy at different lag orders.

\begin{tabular}{|c|c|c|c|c|c|c|c|}
\hline \multirow{2}{*}{ Model } & \multirow{2}{*}{ Index } & \multicolumn{6}{|c|}{ Lag order } \\
\hline & & 13 & 20 & 25 & 30 & 35 & 40 \\
\hline \multirow{4}{*}{ Beta-MIDAS } & $R^{2}$ & 0.8629 & 0.8629 & 0.8629 & 0.8630 & 0.8675 & 0.8680 \\
\hline & RMSE & 0.6430 & 0.6407 & 0.6430 & 0.6445 & 0.6300 & 0.6359 \\
\hline & MSFE & 0.4134 & 0.4105 & 0.4134 & 0.4154 & 0.3969 & 0.4044 \\
\hline & DMSFE & 0.1044 & 0.1041 & 0.1044 & 0.1046 & 0.1026 & 0.1044 \\
\hline \multirow{4}{*}{ Beta-nonzero-MIDAS } & $R^{2}$ & 0.8628 & 0.8631 & 0.8633 & 0.8633 & 0.8677 & 0.8675 \\
\hline & RMSE & 0.6382 & 0.6408 & 0.6421 & 0.6458 & 0.6331 & 0.6327 \\
\hline & MSFE & 0.4073 & 0.4107 & 0.4123 & 0.4171 & 0.4009 & 0.4003 \\
\hline & DMSFE & 0.1032 & 0.1042 & 0.1047 & 0.1053 & 0.1034 & 0.1031 \\
\hline \multirow{4}{*}{ Exp Almon-MIDAS } & $R^{2}$ & 0.8629 & 0.8629 & 0.8629 & 0.8629 & 0.8675 & 0.8675 \\
\hline & RMSE & 0.6429 & 0.6429 & 0.6429 & 0.6429 & 0.6324 & 0.6324 \\
\hline & MSFE & 0.4133 & 0.4133 & 0.4133 & 0.4133 & 0.4000 & 0.4000 \\
\hline & DMSFE & 0.1044 & 0.1044 & 0.1044 & 0.1044 & 0.1031 & 0.1031 \\
\hline \multirow{4}{*}{ U-MIDAS } & $R^{2}$ & 0.8908 & 0.8937 & 0.9011 & 0.9038 & 0.9120 & 0.9201 \\
\hline & RMSE & 0.7368 & 0.7863 & 0.8514 & 0.8703 & 0.8488 & 0.8936 \\
\hline & MSFE & 0.5429 & 0.6183 & 0.7249 & 0.7575 & 0.7204 & 0.7986 \\
\hline & DMSFE & 0.1336 & 0.1412 & 0.1661 & 0.1773 & 0.1826 & 0.1799 \\
\hline \multirow{4}{*}{ Stepfun-MIDAS } & $R^{2}$ & 0.8796 & 0.8803 & 0.8858 & 0.8852 & 0.8897 & 0.8916 \\
\hline & RMSE & 0.7100 & 0.7160 & 0.7483 & 0.7358 & 0.7004 & 0.7181 \\
\hline & MSFE & 0.5041 & 0.5127 & 0.5600 & 0.5414 & 0.4906 & 0.5156 \\
\hline & DMSFE & 0.1370 & 0.1348 & 0.1463 & 0.1459 & 0.1470 & 0.1487 \\
\hline \multirow{4}{*}{ Almon-MIDAS } & $R^{2}$ & 0.8716 & 0.8682 & 0.8717 & 0.8695 & 0.8751 & 0.8750 \\
\hline & RMSE & 0.5046 & 0.5868 & 0.7108 & 0.6905 & 0.6276 & 0.5997 \\
\hline & MSFE & 0.2546 & 0.3443 & 0.5052 & 0.4768 & 0.3939 & 0.3597 \\
\hline & DMSFE & 0.0868 & 0.0942 & 0.1342 & 0.1319 & 0.1216 & 0.1068 \\
\hline
\end{tabular}

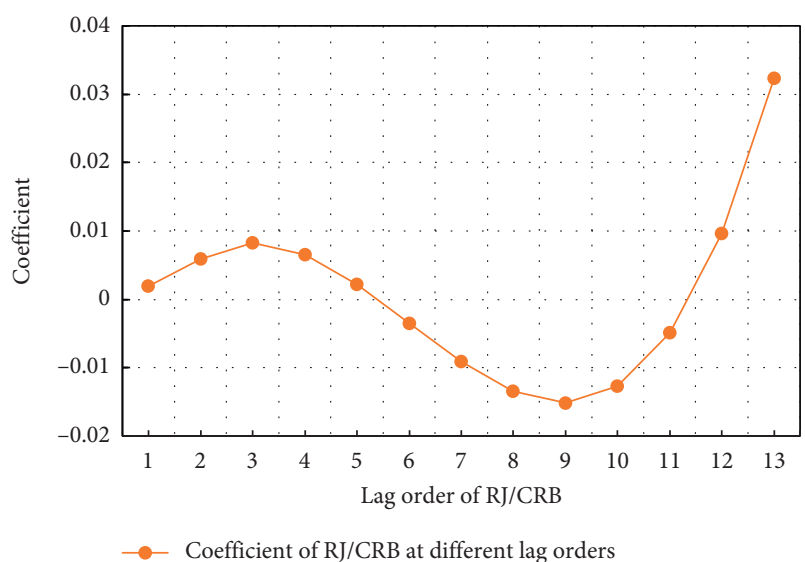

Figure 2: The coefficient fluctuation of Almon-MIDAS at lag order 13.

estimated by the Almon-AR(1)-MIDAS (13) is $(-0.02,0.04)$, that is, the RJ/CRB International Commodity Futures Index has both positive and negative effects on the CPI. The firstorder delay effect is -0.0019 , that is, the RJ/CRB International Commodity Futures Index on the previous trading day will cause the CPI to fall this month by 0.0019 units. The impact of the RJ/CRB International Commodity Futures Index on the CPI this month will last for 13 trading days.

When the explanatory variable is average daily coal consumption of six power plants, the goodness of fit and insample and out-of-sample prediction accuracy at different lag orders are shown in Table 2. Table 2 shows that
Stepfun-AR(1)-MIDAS has the highest goodness of fit among the six models when the lag order increases to 20 or higher, indicating that when the lag order increases, the fitting effect of Stepfun-AR(1)-MIDAS has gradually become prominent. Moreover, when the lag order reaches 22, the RMSE, MSFE, and DMSFE of Stepfun-MIDAS are 0.5055, 0.255 , and 0.0793 , respectively, which are all the lowest. Therefore, Stepfun-AR(1)-MIDAS (22) has the best fitting effect and prediction accuracy, indicating that the impact of the average daily coal consumption of the six major power plants on the CPI is relatively long term and durable, and the duration is about one month. Figure 3 shows that the 22 coefficients estimated by the Stepfun-AR(1)-MIDAS (22) model fluctuate randomly between -0.006 and 0.01 . The lagging influence of the six major power plants' average daily coal consumption on the CPI presents both positive and negative effects. At first, the average daily coal consumption of the six major power plants positively affected the CPI. The increase in the average daily coal consumption of the six major power plants would increase the CPI this month, but the effect gradually turned negative as it approached the end of the month. The impact of the average daily coal consumption of the six major power plants on the CPI will extend to 22 trading days.

When the explanatory variable is Nanhua Futures Commodity Index, the goodness of fit and in-sample and out-of-sample prediction accuracy at different lag orders are shown in Table 3. When the lag order increases to 15 , the prediction effect of Almon-AR(1)-MIDAS is better than 
TABLE 2: Average daily coal consumption of six power plants: the goodness of fit and in-sample and out-of-sample prediction accuracy at different lag orders.

\begin{tabular}{|c|c|c|c|c|c|c|c|}
\hline \multirow{2}{*}{ Model } & \multirow{2}{*}{ Index } & \multicolumn{6}{|c|}{ Lag order } \\
\hline & & 15 & 22 & 25 & 30 & 35 & 40 \\
\hline \multirow{4}{*}{ Beta-MIDAS } & $R^{2}$ & 0.8727 & 0.8728 & 0.8728 & 0.8685 & 0.8709 & 0.8709 \\
\hline & RMSE & 0.5778 & 0.5829 & 0.5831 & 0.5444 & 0.5451 & 0.5451 \\
\hline & MSFE & 0.3339 & 0.3398 & 0.3400 & 0.2964 & 0.2972 & 0.2972 \\
\hline & DMSFE & 0.0947 & 0.0946 & 0.0946 & 0.0834 & 0.0840 & 0.0840 \\
\hline \multirow{4}{*}{ Beta-nonzero-MIDAS } & $R^{2}$ & 0.8619 & 0.8599 & 0.8598 & 0.8598 & 0.8655 & 0.8652 \\
\hline & RMSE & 0.5691 & 0.5496 & 0.5439 & 0.5396 & 0.5373 & 0.5412 \\
\hline & MSFE & 0.3239 & 0.3021 & 0.2959 & 0.2912 & 0.2887 & 0.2929 \\
\hline & DMSFE & 0.0972 & 0.0888 & 0.0865 & 0.0852 & 0.0858 & 0.0867 \\
\hline \multirow{4}{*}{ Exp Almon-MIDAS } & $R^{2}$ & 0.8728 & 0.8728 & 0.8728 & 0.8728 & 0.8740 & 0.8740 \\
\hline & RMSE & 0.5824 & 0.5824 & 0.5824 & 0.5824 & 0.5745 & 0.5745 \\
\hline & MSFE & 0.3392 & 0.3392 & 0.3392 & 0.3392 & 0.3301 & 0.3301 \\
\hline & DMSFE & 0.0945 & 0.0945 & 0.0945 & 0.0945 & 0.0924 & 0.0924 \\
\hline \multirow{4}{*}{ U-MIDAS } & $R^{2}$ & 0.9034 & 0.9066 & 0.9093 & 0.9177 & 0.9302 & 0.9325 \\
\hline & RMSE & 0.6375 & 0.5952 & 0.6266 & 0.5850 & 0.5734 & 0.5657 \\
\hline & MSFE & 0.4064 & 0.3543 & 0.3927 & 0.3422 & 0.3288 & 0.3200 \\
\hline & DMSFE & 0.1001 & 0.0936 & 0.1000 & 0.0506 & 0.0564 & 0.0700 \\
\hline \multirow{4}{*}{ Stepfun-MIDAS } & $R^{2}$ & 0.8879 & 0.8896 & 0.8899 & 0.8898 & 0.9065 & 0.9059 \\
\hline & RMSE & 0.5181 & 0.5055 & 0.5217 & 0.5231 & 0.5237 & 0.5171 \\
\hline & MSFE & 0.2684 & 0.2555 & 0.2722 & 0.2736 & 0.2743 & 0.2674 \\
\hline & DMSFE & 0.0806 & 0.0793 & 0.0858 & 0.0828 & 0.0790 & 0.0758 \\
\hline \multirow{4}{*}{ Almon-MIDAS } & $R^{2}$ & 0.8862 & 0.8874 & 0.8873 & 0.8873 & 0.8987 & 0.8972 \\
\hline & RMSE & 0.5168 & 0.5187 & 0.5202 & 0.5234 & 0.5184 & 0.5295 \\
\hline & MSFE & 0.2671 & 0.2690 & 0.2706 & 0.2740 & 0.2688 & 0.2804 \\
\hline & DMSFE & 0.0756 & 0.0791 & 0.0810 & 0.0758 & 0.0606 & 0.0772 \\
\hline
\end{tabular}

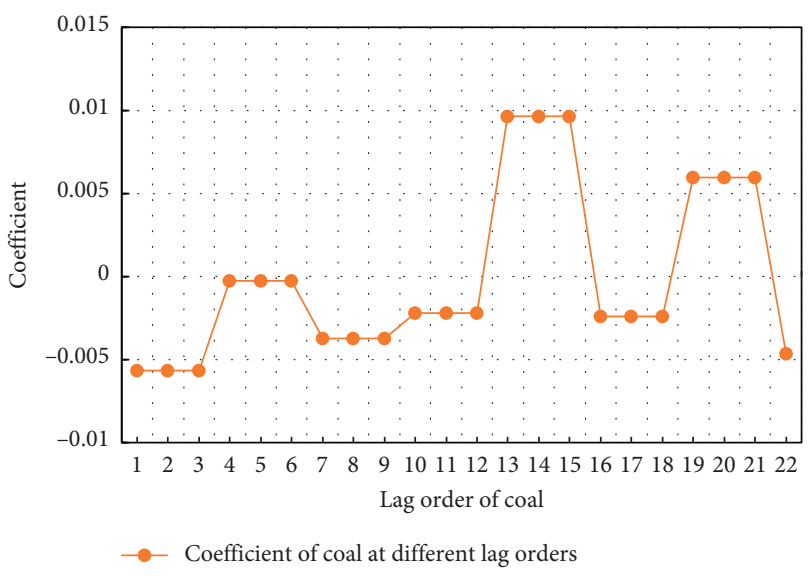

Figure 3: The coefficient fluctuation of Stepfun-MIDAS at lag order 22.

other models. When the lag order further increases, each model's goodness of fit also shows an increasing trend, and the RMSE generally changes in the same direction as the goodness of fit. In terms of prediction accuracy, the prediction accuracy of Exp-Almon-AR(1)-MIDAS model has been maintained at a relatively stable level. The RMSE is stable between 0.49 and 0.50 , and the prediction effect is more stable than other models. When the lag order changes to 23, RMSE, MSFE, and DMSFE of the Almon-AR(1)MIDAS are $0.4715,0.2223$, and 0.0876 , respectively, which are lower than other models. When the lag order increases again, the prediction accuracy of the Almon-AR(1)-MIDAS model begins to decrease. After comparing different models and comparing different lag orders, when the lag order changes to order 23 , the fitting effect and prediction accuracy of the Almon-AR(1)-MIDAS(23) model are relatively better. It can be seen from Figure 4 that the 23 coefficients estimated by the Almon-AR(1)-MIDAS model fluctuate randomly between -0.001 and 0.002 . The lagging influence of the Nanhua Commodity Index on the CPI also has positive and negative situations, but the total delay effect is positive. The first-order delay effect of the Nanhua Futures Commodity Index on the CPI is 0.0016, that is, the growth of the Nanhua Futures Commodity Index will increase the CPI, and the impact on the CPI will extend to 23 trading days, that is, the CPI this month happened to be affected by the fluctuation of the Nanhua Futures Commodity Index.

When the explanatory variable is the exchange rate, the goodness of fit and in-sample and out-of-sample prediction accuracy at different lag orders are shown in Table 4. Table 4 shows that the goodness of fit and prediction accuracy of Beta-AR(1)-MIDAS, Beta-nonzero-AR(1)-MIDAS, and Exp Almon-AR(1)-MIDAS models are close at each order, with no significant difference. The goodness of fit of the U-MIDAS model is slightly better than other models, but the prediction accuracy is inferior to other models at higher orders. When the lag order reaches 20, the values of U-AR(1)MIDAS prediction accuracy indicators RMSE, MSFE, and DMSFE are $0.4669,0.2180$, and 0.1210 , respectively which 
TABLE 3: Nanhua futures commodity index: the goodness of fit and in-sample and out-of-sample prediction accuracy at different lag orders.

\begin{tabular}{|c|c|c|c|c|c|c|c|}
\hline \multirow{2}{*}{ Model } & \multirow{2}{*}{ Index } & \multicolumn{6}{|c|}{ Lag order } \\
\hline & & 15 & 20 & 23 & 25 & 30 & 35 \\
\hline \multirow{4}{*}{ Beta-MIDAS } & $R^{2}$ & 0.8653 & 0.8652 & 0.8651 & 0.8650 & 0.8649 & 0.8691 \\
\hline & RMSE & 0.4999 & 0.5002 & 0.5003 & 0.5004 & 0.5006 & 0.5059 \\
\hline & MSFE & 0.2499 & 0.2502 & 0.2503 & 0.2504 & 0.2506 & 0.2560 \\
\hline & DMSFE & 0.0775 & 0.0775 & 0.0774 & 0.0774 & 0.0773 & 0.0779 \\
\hline \multirow{4}{*}{ Beta-nonzero-MIDAS } & $R^{2}$ & 0.8644 & 0.8641 & 0.8641 & 0.8640 & 0.8641 & 0.8685 \\
\hline & RMSE & 0.5020 & 0.5024 & 0.5025 & 0.5026 & 0.5019 & 0.5079 \\
\hline & MSFE & 0.2520 & 0.2524 & 0.2525 & 0.2526 & 0.2519 & 0.2579 \\
\hline & DMSFE & 0.0771 & 0.0767 & 0.0765 & 0.0763 & 0.0759 & 0.0766 \\
\hline \multirow{4}{*}{ Exp Almon-MIDAS } & $R^{2}$ & 0.8657 & 0.8657 & 0.8657 & 0.8657 & 0.8657 & 0.8699 \\
\hline & RMSE & 0.4986 & 0.4986 & 0.4986 & 0.4986 & 0.4986 & 0.5038 \\
\hline & MSFE & 0.2486 & 0.2486 & 0.2486 & 0.2486 & 0.2486 & 0.2538 \\
\hline & DMSFE & 0.0777 & 0.0777 & 0.0777 & 0.0777 & 0.0777 & 0.0782 \\
\hline \multirow{4}{*}{ U-MIDAS } & $R^{2}$ & 0.8872 & 0.8941 & 0.8944 & 0.8955 & 0.9009 & 0.9086 \\
\hline & RMSE & 0.5172 & 0.5581 & 0.5680 & 0.5851 & 0.6180 & 0.6347 \\
\hline & MSFE & 0.2675 & 0.3115 & 0.3227 & 0.3424 & 0.3820 & 0.4029 \\
\hline & DMSFE & 0.0878 & 0.0912 & 0.0959 & 0.1047 & 0.1184 & 0.1344 \\
\hline \multirow{4}{*}{ Stepfun-MIDAS } & $R^{2}$ & 0.8709 & 0.8758 & 0.8761 & 0.8762 & 0.8816 & 0.8902 \\
\hline & RMSE & 0.5130 & 0.5491 & 0.5395 & 0.5486 & 0.5625 & 0.5866 \\
\hline & MSFE & 0.2631 & 0.3015 & 0.2911 & 0.3009 & 0.3165 & 0.3441 \\
\hline & DMSFE & 0.0866 & 0.0948 & 0.0909 & 0.0961 & 0.0925 & 0.1073 \\
\hline \multirow{4}{*}{ Almon-MIDAS } & $R^{2}$ & 0.8694 & 0.8683 & 0.8685 & 0.8688 & 0.8696 & 0.8723 \\
\hline & RMSE & 0.4785 & 0.4736 & 0.4715 & 0.4775 & 0.5803 & 0.4907 \\
\hline & MSFE & 0.2290 & 0.2243 & 0.2223 & 0.2280 & 0.3368 & 0.2408 \\
\hline & DMSFE & 0.0835 & 0.0895 & 0.0876 & 0.0835 & 0.0919 & 0.0808 \\
\hline
\end{tabular}

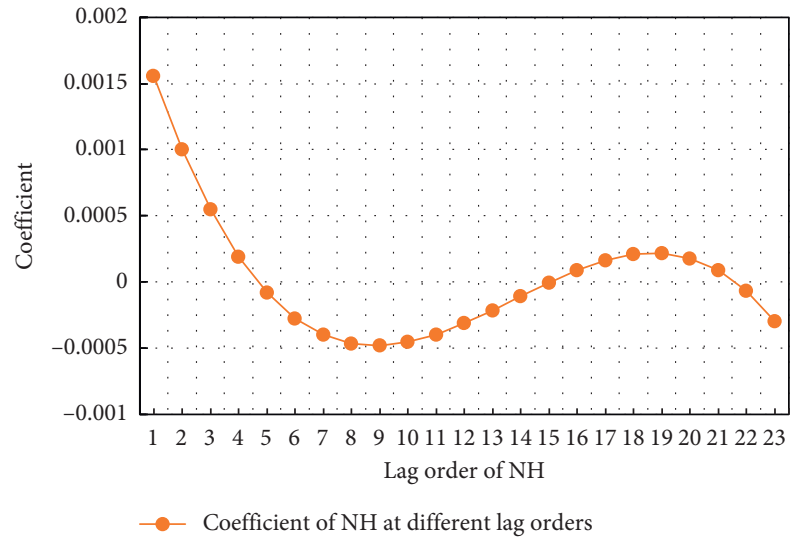

FIGURE 4: The coefficient fluctuation of Almon-MIDAS at lag order 23.

are the lowest among all models and lag order. Therefore, it can be seen from Table 3 that when the exchange rate lag order is 20, the U-AR(1)-MIDAS (20) model has the best prediction performance and can extract the potential information of high-frequency data to the maximum. Figure 5 shows that the 20 coefficients estimated by the U-AR(1)-MIDAS (20) model make random fluctuations in the positive and negative directions between -20 and 15 . The first-order effect of delay is 1.26 , that is, the rise in the exchange rate of USD/RMB on the previous trading day will drive the CPI increase of this month by 1.26 units. The influence of USD/RMB's exchange rate on the CPI of this month will last 20 trading days.

5.2. Multivariate MIDAS Model. In the univariate MIDAS model, the prediction results obtained by different high-frequency explanatory variables will be different. And, there are multiple routes through which price fluctuations can be transmitted, so it is impossible to use a univariate model to predict the CPI accurately. In this part, we consider combining univariate models from different routes to reduce prediction errors. By combining the information contained in different variables, the forecast accuracy of the model can be optimized. The combined prediction model can refer to [26]. In addition, we chose four different weight functions as follows:

Equal weight function:

$$
\omega_{i, t}=\frac{1}{n}
$$

AIC weight function:

$$
\omega_{i, t}=\frac{\exp \left(-\mathrm{AIC}_{i}\right)}{\sum_{i=1}^{n} \exp \left(-\mathrm{AIC}_{i}\right)} .
$$

BIC weight function:

$$
\omega_{i, t}=\frac{\exp \left(-\mathrm{BIC}_{i}\right)}{\sum_{i=1}^{n} \exp \left(-\mathrm{BIC}_{i}\right)}
$$


TABLE 4: Exchange rate: the goodness of fit and in-sample and out-of-sample prediction accuracy at different lag orders.

\begin{tabular}{|c|c|c|c|c|c|c|c|}
\hline \multirow{2}{*}{ Model } & \multirow{2}{*}{ Index } & \multicolumn{6}{|c|}{ Lag order } \\
\hline & & 15 & 20 & 25 & 30 & 35 & 40 \\
\hline \multirow{4}{*}{ Beta-MIDAS } & $R^{2}$ & 0.8617 & 0.8621 & 0.8619 & 0.8619 & 0.8664 & 0.8668 \\
\hline & RMSE & 0.4903 & 0.4863 & 0.4873 & 0.4877 & 0.5004 & 0.4938 \\
\hline & MSFE & 0.2404 & 0.2364 & 0.2375 & 0.2378 & 0.2504 & 0.2439 \\
\hline & DMSFE & 0.0770 & 0.0778 & 0.0779 & 0.0777 & 0.0797 & 0.0793 \\
\hline \multirow{4}{*}{ Beta-nonzero-MIDAS } & $R^{2}$ & 0.8616 & 0.8617 & 0.8617 & 0.8617 & 0.8663 & 0.8664 \\
\hline & RMSE & 0.4938 & 0.4916 & 0.4907 & 0.4896 & 0.5018 & 0.5007 \\
\hline & MSFE & 0.2438 & 0.2417 & 0.2408 & 0.2397 & 0.2518 & 0.2507 \\
\hline & DMSFE & 0.0781 & 0.0780 & 0.0779 & 0.0778 & 0.0798 & 0.0798 \\
\hline \multirow{4}{*}{ Exp Almon-MIDAS } & $R^{2}$ & 0.8618 & 0.8620 & 0.8619 & 0.8620 & 0.8666 & 0.8668 \\
\hline & RMSE & 0.4887 & 0.4875 & 0.4871 & 0.4837 & 0.4972 & 0.4929 \\
\hline & MSFE & 0.2388 & 0.2377 & 0.2373 & 0.2340 & 0.2472 & 0.2430 \\
\hline & DMSFE & 0.0770 & 0.0782 & 0.0780 & 0.0778 & 0.0803 & 0.0793 \\
\hline \multirow{4}{*}{ U-MIDAS } & $R^{2}$ & 0.8810 & 0.8843 & 0.8918 & 0.9054 & 0.9230 & 0.9302 \\
\hline & RMSE & 0.5246 & 0.4669 & 0.5415 & 0.7292 & 0.7439 & 0.8527 \\
\hline & MSFE & 0.2752 & 0.2180 & 0.2932 & 0.5318 & 0.5534 & 0.7271 \\
\hline & DMSFE & 0.1430 & 0.1210 & 0.1751 & 0.3701 & 0.3777 & 0.4827 \\
\hline \multirow{4}{*}{ Stepfun-MIDAS } & $R^{2}$ & 0.8627 & 0.8641 & 0.8661 & 0.8700 & 0.8813 & 0.8829 \\
\hline & RMSE & 0.4763 & 0.4839 & 0.4977 & 0.5728 & 0.6078 & 0.6080 \\
\hline & MSFE & 0.2268 & 0.2342 & 0.2477 & 0.3281 & 0.3694 & 0.3696 \\
\hline & DMSFE & 0.0736 & 0.0996 & 0.0990 & 0.1826 & 0.1980 & 0.1986 \\
\hline \multirow{4}{*}{ Almon-MIDAS } & $R^{2}$ & 0.6872 & 0.6935 & 0.6976 & 0.7051 & 0.7103 & 0.7221 \\
\hline & RMSE & 0.4906 & 0.4909 & 0.5023 & 0.5012 & 0.4973 & 0.4986 \\
\hline & MSFE & 0.2407 & 0.2410 & 0.2523 & 0.2512 & 0.2473 & 0.2486 \\
\hline & DMSFE & 0.0780 & 0.0780 & 0.0796 & 0.0794 & 0.0810 & 0.0796 \\
\hline
\end{tabular}

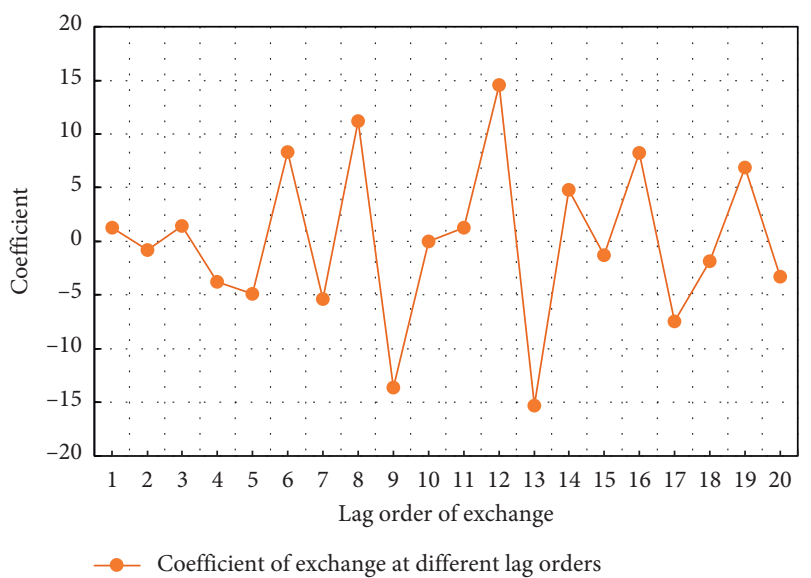

Figure 5: The coefficient fluctuation of U-MIDAS at lag order 20.

MSFE weight function:

$$
\begin{aligned}
& \omega_{i, t}=\frac{m_{i, t}^{-1}}{\sum_{i=1}^{n} m_{i, t}^{-1}}, \\
& m_{i, t}=\sum_{i=T_{0}}^{i} \delta^{t-i}\left(y_{s+h}^{h}-\hat{y}_{i, s+h \mid s}^{h}\right)^{2},
\end{aligned}
$$

$\delta=1$ when using MSFE weight function, $\delta=0.9$ when using DMSFE weight function.

We introduced control variables and intermediate variables into the model. We selected the average daily coal consumption of the six power plants as the intermediate variables, and the Nanhua Futures Commodity Index, and the exchange rate as the control variables. We introduce the cross-multiplication of RJ/CRB International Commodity Futures Index, Nanhua Futures Commodity Index, and exchange rate to reflect the moderating effect. We introduce the cross-multiplication of the average daily coal consumption of the six power plants, the Nanhua Futures Commodity Index, and the exchange rate to reflect the mediating effect. According to each high-frequency explanatory variable's optimal weight function and optimal lag order, we construct a combined forecasting model to make out-of-sample forecasts for the CPI from January 2019 to January 2020. Table 5 shows the goodness of fit and prediction accuracy at the optimal lag order of each crossmultiplication variable.

5.2.1. Combined Forecast of the International Commodity Futures Market and the Domestic Production Sector. According to the univariate model results in Table 6, the AR(1)-MIDAS(13) model with MSFE weight function is better than other models in the goodness of fit and prediction accuracy. Therefore, this model is more suitable for out-of-sample CPI forecast under the material economy transmission route.

5.2.2. Combined Forecast of the International Commodity Futures Market, Chinese Commodity Futures Market, and Domestic Production Sector. According to the results in 
TABLE 5: The goodness of fit and prediction accuracy at the optimal lag order of each cross-multiplication variable.

\begin{tabular}{|c|c|c|c|c|c|c|}
\hline Model & Index & $\begin{array}{c}\mathrm{CRB} \times \text { coal } \\
\mathrm{Lag}=36\end{array}$ & $\begin{array}{c}\mathrm{NH} \times \text { coal } \\
\mathrm{Lag}=24\end{array}$ & $\begin{array}{c}\text { Exchange } \times \text { coal } \\
\text { Lag }=22\end{array}$ & $\begin{array}{c}\mathrm{CRB} \times \mathrm{NH} \\
\mathrm{Lag}=37\end{array}$ & $\begin{array}{c}\mathrm{CRB} \times \text { exchange } \\
\mathrm{Lag}=24\end{array}$ \\
\hline \multirow{4}{*}{ Beta-MIDAS } & $R^{2}$ & 0.8652 & 0.8602 & 0.8696 & 0.8740 & 0.8657 \\
\hline & RMSE & 0.5542 & 0.5567 & 0.6349 & 0.6626 & 0.6733 \\
\hline & MSFE & 0.3072 & 0.3100 & 0.4031 & 0.4390 & 0.4534 \\
\hline & DMSFE & 0.0882 & 0.0901 & 0.1044 & 0.1017 & 0.1099 \\
\hline \multirow{4}{*}{ Beta-nonzero-MIDAS } & $R^{2}$ & 0.8668 & 0.8582 & 0.8598 & 0.8735 & 0.8665 \\
\hline & RMSE & 0.5792 & 0.5502 & 0.5404 & 0.6665 & 0.6772 \\
\hline & MSFE & 0.3355 & 0.3028 & 0.2921 & 0.4442 & 0.4586 \\
\hline & DMSFE & 0.0947 & 0.0893 & 0.0853 & 0.1018 & 0.1116 \\
\hline \multirow{4}{*}{ Exp Almon-MIDAS } & $R^{2}$ & 0.8659 & 0.8615 & 0.8706 & 0.8742 & 0.8659 \\
\hline & RMSE & 0.5222 & 0.5662 & 0.6259 & 0.6646 & 0.6794 \\
\hline & MSFE & 0.2727 & 0.3206 & 0.3917 & 0.4417 & 0.4616 \\
\hline & DMSFE & 0.0837 & 0.0920 & 0.1034 & 0.1024 & 0.1111 \\
\hline \multirow{4}{*}{ U-MIDAS } & $R^{2}$ & 0.9316 & 0.9095 & 0.9070 & 0.9220 & 0.9020 \\
\hline & RMSE & 0.5205 & 0.5288 & 0.5906 & 0.8027 & 0.8192 \\
\hline & MSFE & 0.2710 & 0.2796 & 0.3488 & 0.6443 & 0.6711 \\
\hline & DMSFE & 0.0626 & 0.0769 & 0.0981 & 0.1264 & 0.1475 \\
\hline \multirow{4}{*}{ Stepfun-MIDAS } & $R^{2}$ & 0.9096 & 0.8919 & 0.8907 & 0.8940 & 0.8868 \\
\hline & RMSE & 0.5118 & 0.4745 & 0.4944 & 0.7087 & 0.7423 \\
\hline & MSFE & 0.2619 & 0.2252 & 0.2444 & 0.5022 & 0.5509 \\
\hline & DMSFE & 0.0742 & 0.0722 & 0.0798 & 0.1295 & 0.1378 \\
\hline \multirow{4}{*}{ Almon-MIDAS } & $R^{2}$ & 0.9043 & 0.8870 & 0.8885 & 0.8778 & 0.8731 \\
\hline & RMSE & 0.4911 & 0.4863 & 0.5091 & 0.6344 & 0.5910 \\
\hline & MSFE & 0.2412 & 0.2365 & 0.2592 & 0.4024 & 0.3493 \\
\hline & DMSFE & 0.0613 & 0.0679 & 0.0809 & 0.1054 & 0.0933 \\
\hline
\end{tabular}

TABLE 6: The goodness of fit and prediction accuracy of RJ/CRB and coal.

\begin{tabular}{lcccc}
\hline \multirow{2}{*}{ Weight function } & \multicolumn{4}{c}{ The goodness of fit and prediction accuracy } \\
& & $\operatorname{Lag}=13$ & $\mathrm{Lag}=22$ & $\mathrm{Lag}=36$ \\
\hline \multirow{3}{*}{ MSFE } & $R^{2}$ & 0.8389 & 0.8303 & 0.8320 \\
& $\mathrm{RMSE}$ & 0.5346 & 0.5644 & 0.5552 \\
& $\mathrm{MSFE}$ & 0.2858 & 0.3186 & 0.3083 \\
\hline \multirow{3}{*}{ DMSFE } & $R^{2}$ & 0.8373 & 0.8315 & 0.8273 \\
& $\mathrm{RMSE}$ & 0.5359 & 0.5691 & 0.5539 \\
& $\mathrm{MSFE}$ & 0.2872 & 0.3238 & 0.3068 \\
\hline \multirow{4}{*}{ AIC } & $R^{2}$ & 0.7736 & 0.7681 & 0.8225 \\
& $\mathrm{RMSE}$ & 0.5821 & 0.5585 & 0.5346 \\
BIC & $\mathrm{MSFE}$ & 0.3388 & 0.3120 & 0.2858 \\
\hline \multirow{4}{*}{ Equal weight } & $R^{2}$ & 0.7736 & 0.7977 & 0.8225 \\
& $\mathrm{RMSE}$ & 0.5821 & 0.5472 & 0.5346 \\
& $\mathrm{MSFE}$ & 0.3388 & 0.2995 & 0.2858 \\
\hline & $R^{2}$ & 0.8380 & 0.8338 & 0.8387 \\
& $\mathrm{RMSE}$ & 0.5353 & 0.5757 & 0.5597 \\
& $\mathrm{MSFE}$ & 0.2865 & 0.3314 & 0.3133 \\
\hline
\end{tabular}

Table 7, the AR(1)-MIDAS(22) model with AIC weight function is better than other models in the goodness of fit and prediction accuracy. Therefore, this model is more suitable for out-of-sample CPI forecasts under the financial market route.

5.2.3. Combined Forecast of the International Commodity Futures Market, Exchange Rate, and Domestic Production Sector. According to the results in Table 8, the
AR(1)-MIDAS(22) model with MSFE weight function is better than other models in the goodness of fit and prediction accuracy. Therefore, this model is more suitable for out-of-sample forecasts of CPI under the exchange rate route.

5.2.4. Comparison of the Predicted and the Observed CPI. Table 9 shows the goodness of fit and prediction accuracy of combined forecasting model under three routes. The forecast CPI under the three routes is weighted and averaged to obtain a total predicted CPI. The comparison of the predicted and the observed CPI is shown in Figure 6. As shown in Figure 6, observed and predicted CPI are consistent in most months, except for February, March, October, November 2019, and January 2020. Changes in CPI in recent months may be ascribed to expected shocks such as price rise during the Chinese Lunar New Year, higher pork prices due to African swine fever, and the COVID-19 epidemic.

5.3. Conclusion. In this paper, four kinds of high-frequency daily data are used to predict China's CPI by using the MIDAS model. The four variables have different effects on China's CPI, and each high-frequency variable has different influence route on China's CPI forecast. Judging from the fit and prediction effect of a single variable, the RJ/CRB commodity price index's optimal lag order is 13 . The optimal lag order of the other three high-frequency day variables representing domestic conditions is 22,23 , and 20. Considering that the data samples selected are all data from 
TABLE 7: The goodness of fit and prediction accuracy of RJ/CRB, NH, and coal.

\begin{tabular}{|c|c|c|c|c|c|c|}
\hline \multirow{2}{*}{ Weight function } & \multicolumn{6}{|c|}{ The goodness of fit and prediction accuracy } \\
\hline & & $\operatorname{Lag}=13$ & Lag $=22$ & $\operatorname{Lag}=23$ & $\operatorname{Lag}=24$ & $\operatorname{Lag}=37$ \\
\hline \multirow{3}{*}{ MSFE } & $R^{2}$ & 0.8328 & 0.8253 & 0.8206 & 0.8215 & 0.8333 \\
\hline & RMSE & 0.5428 & 0.5270 & 0.5403 & 0.5611 & 0.5543 \\
\hline & MSFE & 0.2946 & 0.2777 & 0.2920 & 0.3148 & 0.3073 \\
\hline \multirow{3}{*}{ DMSFE } & $R^{2}$ & 0.8318 & 0.8256 & 0.8221 & 0.8248 & 0.8312 \\
\hline & RMSE & 0.5472 & 0.5439 & 0.5548 & 0.5695 & 0.5549 \\
\hline & MSFE & 0.2994 & 0.2958 & 0.3078 & 0.3244 & 0.3079 \\
\hline \multirow{3}{*}{ AIC } & $R^{2}$ & 0.7791 & 0.7807 & 0.7695 & 0.7685 & 0.7398 \\
\hline & RMSE & 0.5716 & 0.5184 & 0.5310 & 0.5297 & 0.5658 \\
\hline & MSFE & 0.3267 & 0.2687 & 0.2820 & 0.2805 & 0.3202 \\
\hline \multirow{3}{*}{$\mathrm{BIC}$} & $R^{2}$ & 0.7791 & 0.8463 & 0.8462 & 0.8464 & 0.7398 \\
\hline & RMSE & 0.5716 & 0.6954 & 0.6979 & 0.6941 & 0.5658 \\
\hline & MSFE & 0.3267 & 0.4836 & 0.4870 & 0.4818 & 0.3202 \\
\hline \multirow{3}{*}{ Equal weight } & $R^{2}$ & 0.8339 & 0.8308 & 0.8261 & 0.8278 & 0.8383 \\
\hline & RMSE & 0.5534 & 0.5514 & 0.5632 & 0.5799 & 0.5617 \\
\hline & MSFE & 0.3062 & 0.3040 & 0.3172 & 0.3363 & 0.3155 \\
\hline
\end{tabular}

TABLE 8: The goodness of fit and prediction accuracy of RJ/CRB, exchange, and coal.

\begin{tabular}{|c|c|c|c|c|c|}
\hline \multirow{2}{*}{ Weight function } & \multicolumn{5}{|c|}{ The goodness of fit and prediction accuracy } \\
\hline & & $\operatorname{Lag}=13$ & $\operatorname{Lag}=20$ & Lag $=22$ & $\operatorname{Lag}=24$ \\
\hline \multirow{3}{*}{ MSFE } & $R^{2}$ & 0.8408 & 0.8260 & 0.8240 & 0.8254 \\
\hline & RMSE & 0.5455 & 0.5385 & 0.5322 & 0.5594 \\
\hline & MSFE & 0.2975 & 0.2900 & 0.2833 & 0.3130 \\
\hline \multirow{3}{*}{ DMSFE } & $R^{2}$ & 0.8374 & 0.8231 & 0.8231 & 0.8280 \\
\hline & RMSE & 0.5535 & 0.5589 & 0.5537 & 0.5645 \\
\hline & MSFE & 0.3063 & 0.3124 & 0.3066 & 0.3187 \\
\hline \multirow{3}{*}{ AIC } & $R^{2}$ & 0.7673 & 0.7530 & 0.7578 & 0.7516 \\
\hline & RMSE & 0.5824 & 0.5617 & 0.5523 & 0.5631 \\
\hline & MSFE & 0.3391 & 0.3155 & 0.3050 & 0.3171 \\
\hline \multirow{3}{*}{ BIC } & $R^{2}$ & 0.7673 & 0.7579 & 0.7583 & 0.7996 \\
\hline & RMSE & 0.5824 & 0.5636 & 0.5524 & 0.5669 \\
\hline & MSFE & 0.3391 & 0.3177 & 0.3052 & 0.3214 \\
\hline \multirow{3}{*}{ Equal weight } & $R^{2}$ & 0.8402 & 0.8291 & 0.8298 & 0.8289 \\
\hline & RMSE & 0.5582 & 0.5568 & 0.5483 & 0.5696 \\
\hline & MSFE & 0.3116 & 0.3100 & 0.3007 & 0.3244 \\
\hline
\end{tabular}

TABLE 9: The goodness of fit and prediction accuracy of combined forecasting model under three routes.

\begin{tabular}{lcccc}
\hline The goodness of fit and prediction accuracy & Route 1 & Route 2 & Route 3 & Weighted sum \\
\hline$R^{2}$ & 0.8389 & 0.7807 & 0.8240 & 0.8214 \\
RMSE & 0.5346 & 0.5184 & 0.5322 & 0.5208 \\
MSFE & 0.2858 & 0.2687 & 0.2833 & 0.2713 \\
\hline
\end{tabular}

domestic trading days, we can consider 23 trading days consisting of a month, excluding holidays and other factors. Therefore, the three high-frequency daily variables in China can predict CPI more perfectly with the current month's data.

In the material economy route, the $\mathrm{RJ} / \mathrm{CRB}$ commodity price index's direct impact on the CPI fluctuates, but the overall effect is positive. However, the optimal lag order is significantly smaller than other high-frequency explanatory variables, which indicates that the impact of the international commodity futures market on China's CPI is mainly short term. After adding the intermediary variable, the optimal lag order has increased significantly, indicating that the impact of international commodity futures prices on China's industrial output needs a longer time. Therefore, its impact on China's CPI will also have a time lag effect, and RJ/CRB commodity price index has a long-term effect on the CPI.

In the financial market route, after adding the Nanhua Commodity Futures Index as a regulatory variable to the model, the effects of moderating effect and mediating effect are alternating between the positive and the negative. The mediating effect of the Nanhua Commodity Futures Index 


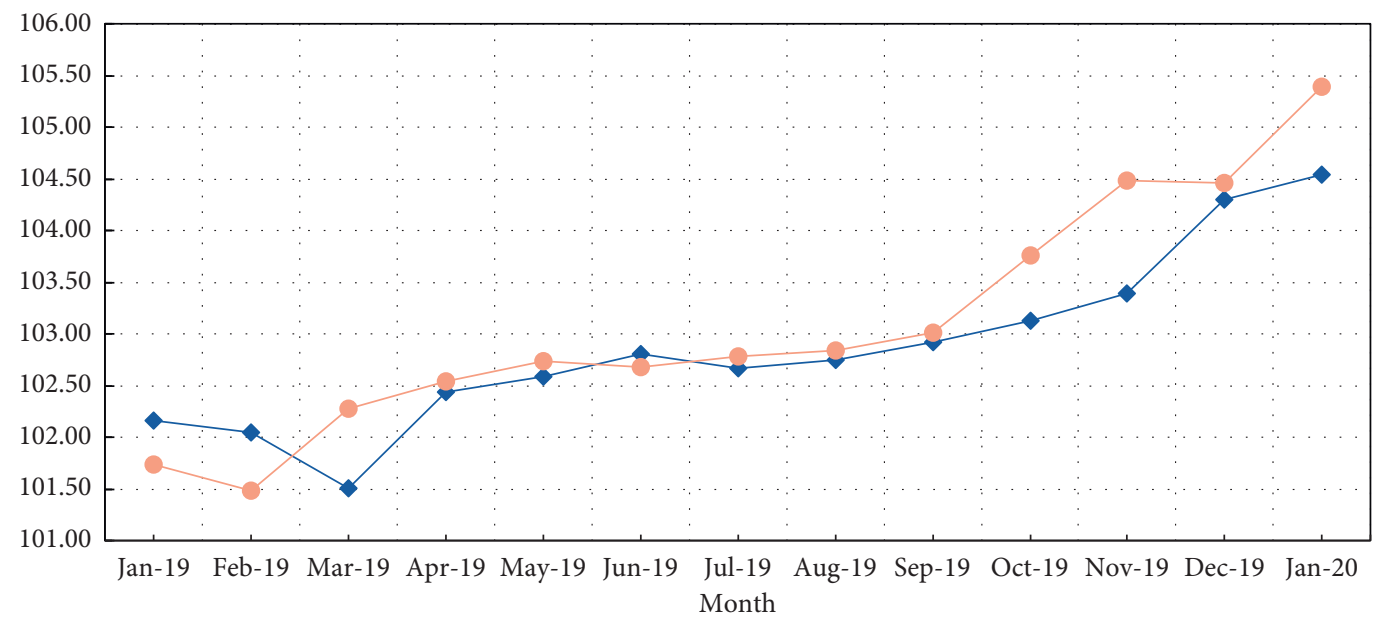

- Predicted CPI

Observed CPI

Figure 6: Predicted CPI vs. observed CPI.

and the average daily coal consumption of the six power plants are unstable for the CPI. The optimal lag order of the moderating effect of the RJ/CRB Commodity Price Index and Nanhua Commodity Futures Index is greater, and their influence on the CPI is longer.

The US dollar to the RMB exchange rate is added as the adjustment variable in the exchange rate route. The optimal lag order of the adjustment variable and the intermediary variable is the same. The effect on the CPI lasts about one month, indicating that this route conducts the domestic CPI more rapidly. The reason may be that exchange rate changes can more directly affect domestic purchasing power, and the real-time effect is more pronounced. In contrast, domestic and foreign financial markets' linkage effect has a short-term time lag, which takes longer to transmit to the domestic production and consumption side.

Based on the univariate model's fit and prediction results, we further construct the combined prediction model and analyze its prediction accuracy and effect. The results show that the combined prediction model with MSFE as the weight in the material economic route, the combined prediction model with AIC as the weight in the financial market route, and the combined prediction model with MSFE as the weight in the exchange rate route have high precision in China's CPI forecast. Finally, integrating the three routes can effectively predict the CPI in a normal month.

\section{Policy Suggestions}

China's strong dependence on international commodities will undoubtedly make the fluctuation of international commodity futures market and domestic economy interrelated. Its price increase will affect China's economic growth and promote inflation, thus affecting the economy's stability. Therefore, preventing and eliminating the risk of external shocks and effectively defusing the shocks caused by price fluctuations in the international commodity market must be considered. This article gives the following suggestions.
First of all, it is necessary to monitor the price change in real time and pay attention to the conduction effect of international commodity futures price fluctuation. Real-time monitoring and capturing the volatility of the international market is the prerequisite for proposing follow-up measures. The previous research and analysis makes it known that the international market price fluctuations will impact domestic industrial and consumer price levels. Simultaneously, the linkage of domestic and foreign futures market is a conduction route that cannot be ignored, and the change of international market price will increase the domestic financial risk. Therefore, real-time monitoring and early warning of international commodity futures prices are indispensable to develop timely and effective strategies to deal with financial uncertainty without risk.

Secondly, identify the main factors that cause fluctuations in international commodity futures prices and effectively resolve different channels' impact. The influence factors of international commodity futures price are very complicated. At different times and under different conduction routes, international commodities' conduction effect on China's economy will be different. Therefore, in dealing with the impact of international prices, it is essential to establish monitoring and early warning mechanisms. Relevant departments should improve the ability to collect and process information on the futures market and make reasonable predictions on important commodities' future trends. In addition, we should improve the ability to identify the dominant factors. According to domestic and foreign economy and finance, the corresponding policy means should be formulated for different transmission channels, monetary policy, and fiscal policy, and administrative intervention should be effectively adopted to guide enterprises to adopt flexible financial instruments to resolve risks.

Third, we must develop the domestic commodity futures market and strive for pricing power. China has a great demand for resources, and bulk commodities such as iron ore and crude oil account for a large proportion of world 
demand. However, under the current trade background, China can only trade following the requirements of foreign exchange, has no right to speak in the process of commodity pricing, and has no advantage in import and export trade. From the research of this article, the fluctuation of international commodity futures prices will be carried out through the linkage of domestic and foreign markets. Therefore, China's futures market needs to be further improved. In terms of countermeasures, China's participation in the formation of international commodity futures prices mainly includes: perfecting the commodity varieties of China's futures market, reasonably exploring the reasons for price changes in the international commodity futures market, combining the background of domestic and foreign markets to forecast its future trends, while guarding against potential imported inflation risks.

Finally, the government should establish a strategic commodity reserve system. Changes in international commodity prices depend on supply and demand factors and are also affected by political factors. Since bulk commodities have strategic reserves, the establishment of a strategic reserve system is of great significance. When prices fluctuate sharply or frequently, the country can use strategic reserves to alleviate the shock caused by price fluctuations. On the one hand, it is necessary to reduce the degree of dependence on imports of bulk commodities. Relevant departments use policy measures to encourage domestic cultivation of agricultural products that are highly dependent on imports and control the industrial sector's demand for bulk commodities to reduce unnecessary consumption. On the other hand, in conjunction with the national development plan, actively expand the overseas sources of commodities, encourage enterprises to invest in overseas resources, and establish strategic cooperative relations with those that produce strategic resources and commodities.

\section{Data Availability}

The data used to support the findings of this study are available from the corresponding author upon request.

\section{Conflicts of Interest}

The authors declare that they have no conflicts of interest regarding the publication of this article.

\section{Acknowledgments}

This research was funded by the National Social Science Fund of China (grant no. 19BJL024).

\section{References}

[1] L. Hong, W. Shu, J. Wang, and R. Mian, "Harmonic resonance investigation of a multi-inverter grid-connected system using resonance modal analysis," IEEE Transactions on Power Delivery, vol. 34, no. 1, pp. 63-72, 2019.

[2] C. Wei, Z. Shen, D. Xiao, L. Wang, X. Bai, and H. Chen, "An optimal scheduling strategy for peer-to-peer trading in interconnected microgrids based on RO and Nash bargaining," Applied Energy, vol. 295, Article ID 117024, 2021.

[3] C. Zhang, J. Fu, and Z. Pu, "A study of the petroleum trade network of countries along "The Belt and Road Initiative"” Journal of Cleaner Production, vol. 222, pp. 593-605, 2019.

[4] C. Zhang, Z. Pu, and Q. Zhou, "Sustainable energy consumption in northeast asia: a case from China's fuel oil futures market,” Sustainability, vol. 10, no. 1, p. 261, 2018.

[5] Z. Pu, J. Fu, C. Zhang, and J. Shao, "Structure decomposition analysis of embodied carbon from transition economies," Technological Forecasting and Social Change, vol. 135, no. 10, pp. 1-12, 2018.

[6] C. Wei, M. Benosman, and T. Kim, "Online parameter identification for state of power prediction of lithium-ion batteries in electric vehicles using extremum seeking," International Journal of Control, Automation and Systems, vol. 17, no. 11, pp. 2906-2916, 2019.

[7] D. Zivkov, J. Uraskovic, and S. Manic, "How do oil price changes affect inflation in Central and Eastern European countries? a wavelet-based Markov switching approach," Baltic Journal of Economics, vol. 19, no. 1, pp. 84-104, 2019.

[8] L. T. Goh, S. H. Law, and I. Trinugroho, "Do oil price fluctuations affect the inflation rate in Indonesia asymmetrically?" The Singapore Economic Review, vol. 7, no. 1, pp. 1-21, 2020.

[9] F. Bec and A. De Gaye, "How do oil price forecast errors impact inflation forecast errors? an empirical analysis from US, French and UK inflation forecasts," Economic Modelling, vol. 53, no. 2, pp. 75-88, 2016.

[10] A. R. Joshi and D. Acharya, "Commodity prices and domestic inflation in India," Global Journal of Emerging Market Economies, vol. 3, no. 2, pp. 223-246, 2011.

[11] C. Estrades and M. I. Terra, "Commodity prices, trade, and poverty in Uruguay," Food Policy, vol. 37, no. 1, pp. 58-66, 2012.

[12] G. Filis and I. Chatziantoniou, "Financial and monetary policy responses to oil price shocks: evidence from oil-importing and oil-exporting countries," Review of Quantitative Finance and Accounting, vol. 42, no. 4, pp. 709-729, 2014.

[13] T. R. Govinda, "Oil prices and the global economy," Energy Economics, vol. 49, no. 5, pp. 669-675, 2015.

[14] T.-H. Le, Y. Chang, and D. Park, "Oil price fluctuations and energy commodity prices: an analysis of asymmetric effects," The Singapore Economic Review, vol. 8, no. 3, pp. 1-23, 2020.

[15] A. M. Herrera, M. B. Karaki, and S. K. Rangaraju, "Oil price shocks and U.S. economic activity," Energy Policy, vol. 129, no. 6, pp. 89-99, 2019.

[16] C. Blattman, J. Hwang, and J. G. Williamson, "Winners and losers in the commodity lottery: the impact of terms of trade growth and volatility in the periphery 1870-1939," Journal of Development Economics, vol. 82, no. 1, pp. 156-179, 2007.

[17] R. Dornbusch and S. Fischer, "Exchange rates and the current account," The American Economic Review, vol. 70, no. 5, pp. 960-971, 1980.

[18] B. Büyükşahin and M. Robe, "Speculators, commodities and cross-market linkages," Journal of International Money and Finance, vol. 42, pp. 38-70, 2014.

[19] J. V. Quadrini, "Macroeconomic effects of financial shocks," Social Science Electronic Publishing, vol. 102, no. 1, pp. 238271, 2012.

[20] R. Hammersland and C. B. Træe, "The financial accelerator and the real economy: a small macroeconometric model for Norway with financial frictions," Economic Modelling, vol. 36, no. 1, pp. 517-537, 2014. 
[21] D. W. Jorgenson, "Capital theory and investment behaviour," American Economic Review, vol. 53, no. 2, pp. 247-259, 1963.

[22] J. Tobin, "A general equilibrium approach to monetary theory," Journal of Money, Credit and Banking, vol. 1, no. 1, pp. 15-29, 1969.

[23] A. Jain and S. Ghosh, "Dynamics of global oil prices, exchange rate and precious metal prices in India," Resources Policy, vol. 38, no. 1, pp. 88-93, 2013.

[24] S. Oliner and G. Rudebusch, "Is there a broad credit channel for monetary policy?" Economic Review, vol. 1, pp. 3-13, 1996.

[25] M. Hume and A. Sentance, "The global credit boom: challenges for macroeconomics and policy," Journal of International Money and Finance, vol. 28, no. 8, pp. 1426-1461, 2009.

[26] E. Andreou, E. Ghysels, and A. Kourtellos, "Should macroeconomic forecasters use daily financial data and how?" Journal of Business and Economic Statistics, vol. 31, no. 2, pp. 240-251, 2013. 